\title{
Could Teriparatide Replace Percutaneous Vertebral Augmentation for Patients with Osteoporotic Vertebral Compression Fracture to Some Extent? [Letter]
}

This article was published in the following Dove Press journal:

Clinical Interventions in Aging

Jiaming Zhou

Yuan Xue (D)

Department of Orthopaedic Surgery, Tianjin Medical University General Hospital, Tianjin, People's Republic of China
Correspondence: Yuan Xue

Department of Orthopaedic Surgery,

Tianjin Medical University General

Hospital, Tianjin, People's Republic of China

Tel +8622 608I4688

Fax +86 22 27219052

Email xueyuanzyy@I63.com

\section{Dear editor}

We read with great interest the article by Kong et al. ${ }^{1}$ In their study, the authors found that for patients with osteoporotic vertebral compression fracture (OVCF), treatment with percutaneous kyphoplasty (PKP) and teriparatide showed a lower risk of new vertebral compression fracture (NVCF) and better clinical outcomes than with PKP and basic treatment (calcium and vitamin D). We wish to express our opinion on this topic.

Osteoporosis is becoming a major public health concern and the most common form of osteoporotic fracture is $\mathrm{OVCF}^{2}{ }^{2}$ Treatment methods include conservative management, percutaneous vertebroplasty (PVP), PKP, and surgical stabilization. When there is an inadequate response of OVCF to conservative therapy of over 3 weeks duration, percutaneous vertebral augmentation can be considered. ${ }^{3}$ However, the high incidence of NVCF after surgery should be noted. In the study, the authors prescribed a 12-month course of teriparatide for OVCF patients after surgery and confirmed its effectiveness in decreasing the incidence of NVCF, improved outcomes and enhanced bone mineral density (BMD). Given the complications of percutaneous vertebral augmentation and the efficacy of teriparatide in OVCF, we hypothesize that teriparatide could replace percutaneous vertebral augmentation in OVCF in appropriate patients.

Teriparatide is the only bone anabolic drug approved for postmenopausal women and men with osteoporosis. ${ }^{4}$ In a study of the drug in patients with repeated and multiple new-onset OVCF, the researchers found significantly improved shortand long-term efficacy, pain scores (visual analogue scale) were significantly reduced over 12 months of follow-up, and no NVCF occurred; therefore, no percutaneous vertebral augmentation was required. ${ }^{5}$ Furthermore, we found that for patients with neurological damage following new unstable OVCF, but who had surgical contraindications, teriparatide was better than alendronate in improving $\mathrm{BMD}$, bone turnover parameters and spinal cord injury. ${ }^{6}$ Likewise, in a recent study, teriparatide showed better efficacy than did bisphosphonate and non-antiosteoporosis methods for the management of OVCF patients, based on a numerical rating scale, vertebral height loss, and the incidence of intravertebral vacuum cleft. ${ }^{7}$ 
A report from the task force convened by the American Society for Bone and Mineral Research indicated that the routine use of vertebral augmentation for pain relief after OVCF is not supported by current evidence. Meanwhile, antiosteoporosis medications were recommended, because of the available evidence from several randomized controlled trials, for their role in reducing the risk of $\mathrm{NVCF}^{8}$ These suggestions are in accordance with our opinions. Based on current studies, teriparatide is a promising treatment for patients with $\mathrm{OVCF}$ compared with other anti-osteoporosis drugs. If it is prescribed for patients who are being considered for percutaneous vertebral augmentation, NVCF, and repeated surgery may be avoided. Considering the cost of teriparatide, we advise that at least treatment with 1-month of teriparatide should be attempted when other conservative methods have failed. If significant improvement occurs, the teriparatide treatment should be continued for 12 months. Further large-populationbased randomized controlled trials are needed to evaluate the efficacy of teriparatide in the treatment of OVCF compared with percutaneous vertebral augmentation.

\section{Disclosure}

The authors report no conflicts of interest in this communication

\section{References}

1. Kong M, Zhou C, Zhu K, et al. 12-month teriparatide treatment reduces new vertebral compression fractures incidence and back pain and improves quality of life after percutaneous kyphoplasty in osteoporotic women. Clin Interv Aging. 2019;14:1693-1703. doi:10.2147/ CIA.S224663

2. McCarthy J, Davis A. Diagnosis and management of vertebral compression fractures. Am Fam Physician. 2016;94(1):44-50.

3. Tsoumakidou G, Too CW, Koch G, et al. CIRSE guidelines on percutaneous vertebral augmentation. Cardiovasc Intervent Radiol. 2017;40 (3):331-342. doi:10.1007/s00270-017-1574-8

4. Neer RM, Arnaud CD, Zanchetta JR, et al. Effect of parathyroid hormone (1-34) on fractures and bone mineral density in postmenopausal women with osteoporosis. $N$ Engl J Med. 2001;344 (19):1434-1441. doi:10.1056/NEJM200105103441904

5. Tu PH, Liu ZH, Lee ST, Chen JF. Treatment of repeated and multiple new-onset osteoporotic vertebral compression fractures with teriparatide. J Clin Neurosci. 2012;19(4):532-535. doi:10.1016/j. jocn.2011.04.048

6. Zhao Y, Xue R, Shi N, et al. Aggravation of spinal cord compromise following new osteoporotic vertebral compression fracture prevented by teriparatide in patients with surgical contraindications. Osteoporosis Int. 2016;27(11):3309-3317. doi:10.1007/s00198-016-3651-2

7. Min HK, Ahn JH, Ha KY, et al. Effects of anti-osteoporosis medications on radiological and clinical results after acute osteoporotic spinal fractures: a retrospective analysis of prospectively designed study. Osteoporosis Int. 2019;30(11):2249-2256. doi:10.1007/s00198-01905125-0

8. Ebeling PR, Akesson K, Bauer DC, et al. The efficacy and safety of vertebral augmentation: a second asbmr task force report. $J$ Bone Mineral Res. 2019;34(1):3-21. doi:10.1002/jbmr.v34.1

Dove Medical Press encourages responsible, free and frank academic debate. The content of the Clinical Interventions in Aging 'letters to the editor' section does not necessarily represent the views of Dove Medical Press, its officers, agents, employees, related entities or the Clinical Interventions in Aging editors. While all reasonable steps have been taken to confirm the content of each letter, Dove Medical Press accepts no liability in respect of the content of any letter, nor is it responsible for the content and accuracy of any letter to the editor.

Clinical Interventions in Aging

Dovepress

\section{Publish your work in this journal}

Clinical Interventions in Aging is an international, peer-reviewed journal focusing on evidence-based reports on the value or lack thereof of treatments intended to prevent or delay the onset of maladaptive correlates of aging in human beings. This journal is indexed on PubMed Central, MedLine, CAS, Scopus and the Elsevier
Bibliographic databases. The manuscript management system is completely online and includes a very quick and fair peer-review system, which is all easy to use. Visit http://www.dovepress.com/ testimonials.php to read real quotes from published authors. 